\title{
Nuevas voces en el desarrollo y la acreditación institucional, una mirada desde las regiones
}

\author{
Juan Camilo Ramírez García ${ }^{1}$ \\ Director de Sedes Regionales Universidad Surcolombiana \\ juanka.ramirez03@gmail.com \\ juan.ramirez@usco.edu.co
}

\section{Introducción}

En medio de una sentida necesidad por fortalecer la oferta académica en el departamento del Huila, en el año de 1995 la Universidad Surcolombiana tomó la iniciativa de crear las sedes de la institución, mediante el acuerdo $027^{2}$ "Por el cual se crean las Sedes de la Universidad Surcolombiana, en los Municipios de Garzón, Pitalito y La Plata" esta iniciativa generó un nuevo capitulo en el desarrollo del Huila, se abrió la posibilidad de estudiar carreras técnicas, tecnológicas y profesionales a personas que por sus condiciones económicas, sociales y hasta culturales no habrían logrado recibir este tipo de formación en las ciudades. La evolución de las sedes a partir de esa fecha ha sido revolucionaria, en las tres sedes se cuenta con una infraestructura propia en la que resaltan la belleza natural que se puede percibir a su alrededor, el perfecto estado de los salones, bloques administrativos y escenarios deportivos; pero adicional a todo esto en los últimos cuatro años se ha logrado direccionar inversiones importantes para la construcción de laboratorios de ciencias básicas, laboratorios de bilingüismo, aulas multimediales, adecuación de Cámara Gesell (laboratorio de psicología), cubiertas de polideportivos, adecuaciones en los restaurantes, dotación de equipos audiovisuales y aires acondicionados, financiación de convocatorias propias de investigación para semilleros y se han logrado vincular un mayor número de docentes visitantes y ocasionales de tiempo completo, contribuyendo a generar un dinamismo propicio para aportar en el desarrollo de las regiones.

En el marco del desarrollo y el IDC $^{3}$ uno de los sucesos más relevantes para la Universidad Surcolombiana se dio el pasado 29 de diciembre de 2017, la institución logró la "Acreditación Institucional de Alta Calidad" 4 , esta distinción nació como resultado de un trabajo disciplinado y articulado, un reconocimiento para la institución, que sin duda recoge un gran esfuerzo en medio de una crisis económica que afectó todos los sectores y redujo considerablemente los ingresos de las Universidades Públicas. Pero un hecho que no pasó desapercibido por los directivos de la institución y la comunidad universitaria en las sedes, se dio por que Ministerio de Educación optó por acreditar todas las sedes de la Universidad, incluyendo en la resolución a Garzón, Pitalito y La Plata, un reconocimiento que sin duda reconforta a los actores regionales pero que a la vez insta a la Universidad a trabajar la renovación de la acreditación bajo los lineamientos multicampus, demandando mayores exigencias para lograr la re-acreditación, pero generando una valiosa oportunidad de generar impactos positivos más fuertes en el desarrollo y competitividad de regiones que requieren una presencia más fuerte

\footnotetext{
${ }^{1}$ Contador Público; Universidad Surcolombiana, Especialista en Gerencia Tributaria; Universidad Surcolombiana, Maestrante en Gerencia Integral de Proyectos; Universidad Surcolombiana.

${ }^{2}$ Acuerdo de Consejo Superior Universitario

3 Índice Departamental de Competitividad

${ }^{4}$ Resolución 29501 de 2017
} 
e incidente en la solución de sus problemas y construcción de su futuro.

\section{De los retos a los cambios necesarios}

La presencia de la institución en los municipios de Garzón, Pitalito y La Plata y sus zonas de influencia ha representado valiosas oportunidades para su población, especialmente en la formación, la Universidad trasladó a las regiones sólo uno de sus tres ejes misionales, entendiendo las limitaciones de recursos físicos, humanos y financieros que permitieran desarrollar investigación y proyección social, pero el panorama actual y los escenarios futuros deseados han llevado a la institución a ir fortaleciendo de manera paulatina los recursos físicos y vinculando recurso humano de tiempo completo en las distintas sedes, buscando siempre anticiparnos al escenario que ya tenemos cerca.

\subsection{Re-Acreditación como el reto que involucra el esfuerzo de todos los actores}

La apuesta mundial que se concentra en los "Objetivos de Desarrollo Sostenible" (ODS) ${ }^{5}$ requiere iniciativas de desarrollo científico, con altos niveles de investigación e innovación que sólo serán posibles a la medida que se fortalezcan las capacidades humanas y se despierte la sensibilidad de aquellos que tienen incidencia en las decisiones, no será posible disminuir las brechas sociales con instituciones de educación superior que se dediquen de manera exclusiva a la formación, se necesita ir más allá, una articulación que permita conseguir los recursos físicos y humanos necesarios para lograr motivar la investigación en las regiones y que esa investigación trascienda a la solución de problemáticas regionales y en la construcción de condiciones que ayuden a generar un mejor futuro para la mayoría de la población.

Hablando un poco de la importancia para todos los actores de tener una universidad fortalecida, es preciso mencionar que el departamento del Huila tan sólo logró una puntuación de 4,43 puntos de 10 en el IDC 2017, entre otras cosas por que en el pilar 7 correspondiente a educación superior y capacitación, demostró una baja cobertura en educación superior con puntuación de 2,83 y teniendo en cuenta que en esa fecha aún no se contaba con universidades acreditadas, el departamento fue calificado con 3,58 en calidad de la educación superior, en donde la variable que más afectó esta puntuación, fue la cobertura instituciones de educación superior con acreditación de alta calidad, en donde se recibió un puntaje de 0,04 .

El hecho de que la Universidad Surcolombiana lograra recibir la Acreditación Institucional incidirá de entrada en mejorar la calificación del IDC 2018 en el factor de eficiencia en donde se evalúa la educación superior, pero además, los logros alcanzados por la Universidad, que le dieron mérito para recibir la Acreditación impactarán de manera positiva el factor de sofisticación e innovación, en especial por el fortalecimiento que la institución ha tenido en la investigación de alta calidad y el desarrollo de patentes.

El pasado 25 de julio de 2018 el Ministerio de Educación Nacional expidió el "Decreto No $1280^{\prime \prime}$ y en ese mismo sentido el 9 de agosto de 2018 el CESU7 expidió el Acuerdo 01 "Por el cual se actualizan los lineamientos para acreditación de alta calidad institucional y de programas de pregrado" quedando claro en su articulo 4, que la Universidad Surcolombiana es una "Institución

\footnotetext{
${ }^{5}$ También conocidos como Objetivos Mundiales, son un llamado universal a la adopción de medidas para poner fin a la pobreza, proteger el planeta y garantizar que todas las personas gocen de paz y prosperidad.

6 "Por el cual se reglamenta el sistema de Aseguramiento de la Calidad de la Educación Superior, el registro calificado de que trata la Ley 1188 de 2008 y los artículos 53 y 54 de la Ley 30 de 1992 sobre acreditación, por lo que se subrogan los Capítulos 2 y 7 del Titulo 3 de la Parte 5 del Libro 2 del Decreto 1075- Único Reglamentario del Sector Educación- "

${ }^{7}$ Consejo Nacional de Educación Superior
} 
Multicampus" 8 y por ende estando los municipios de Garzón, Pitalito y La Plata categorizados en categorías diferentes a la especial, 1 y 2, para la re-acreditación Institucional se deberá fortalecer el plan de regionalización ajustado a: i. Información sobre características de la oferta de programas, ii. Indicadores de resultado de esta oferta, y iii. Condiciones institucionales de la oferta. Esto implica grandes esfuerzos articulados y un trabajo serio que debe involucrar sin duda a todo el departamento.

\section{Conclusión}

Teniendo en cuenta los beneficios de la acreditación institucional para la región y los nuevos lineamientos establecidos que exigen un mayor compromiso para lograr la re-acreditación, se hace necesario el trabajo articulado de todos los actores institucionales y sociales, los retos son ambiciosos y los recursos escasos. La nueva administración de la Universidad Surcolombiana tendrá grandes desafíos y en estos cuatro años se debe buscar en beneficio de las regiones, la ampliación de la oferta académica en las regiones, la vinculación de un mayor número de docentes de tiempo completo que lleguen a fortalecer la investigación y la proyección social en las sedes regionales, pero a la par un mejor bienestar en estos docentes con un mayor número de meses vinculados al año y mejores posibilidades de formación que les permita actualizar de manera periódica sus conocimientos, generando con esto mayor estabilidad en los docentes, para que puedan aportarle la mayor parte de sus energías al desarrollo regional desde la institución. También es necesario seguir fortaleciendo la infraestructura física, la adecuación de nuevos espacios (salones, biblioteca, laboratorios etc), el acceso a bases de datos, la dotación de material bibliográfico actualizado y pertinente, el desarrollo de talleres de lecto-escritura e investigación, y las convocatorias de investigación para semilleros de las sedes.

Es importante destacar que se deja una línea de base favorables con grandes avances como la aprobación del "acuerdo 059 de 2017"9 en el que se da la connotación de Sedes Regionales, se incluye un comité de sedes regionales en la estructura orgánica y se incluye al Director de Sedes Regionales en el Comité Administrativo y el Comité de Permanencia y Graduación; se fortaleció el personal administrativo, y docente; se aprobaron los acuerdos para el recaudo de estampilla municipal en Garzón, Pitalito y La Plata, se estableció en la "Ordenanza 005 de $2017 " 10$ que mínimo el $30 \%$ del recaudo total de estampilla que le corresponde a la Universidad, debe ir dirigido a las sedes de Garzón, Pitalito y La Plata; y se deja avanzada la construcción de la política de regionalización. Será necesario aprobar la inclusión del Director de Sedes Regionales en el Consejo Académico y flexibilizar la venta de servicios en sedes para lograr generar mayores recursos y es en este sentido que el reto más grande será generar condiciones de autosuficiencia para que cada región se encargue de orientar el camino y generar el desarrollo con la eficiencia, eficacia y la pertinencia en el uso de los recursos.

\footnotetext{
${ }^{8}$ Aquellas que tienen oferta académica distribuida geográficamente en sedes diferentes al domicilio principal pero que cumplen con los siguientes elementos comunes: i. El mismo nombre o razón social, ii. Un único propósito institucional expresado en una misión común, iii. Un sistema de gobierno centralizado a un órgano máximo de gobierno, y iv. Un mismo conjunto de normas para la gestión institucional (estatutos, reglamentos, políticas académicas, sistema interno de aseguramiento de la calidad)"

${ }^{9}$ Por el cual se expide el Estatuto de Estructura Orgánica y se determinan las funciones de las dependencias académicas y administrativas de la Universidad Surcolombiana

${ }^{10}$ Por medio de la cual se reanuda el cobro de la estampilla prodesarrollo de la Universidad Surcolombiana en el departamento del Huila y se deroga la ordenanza 049 del 2002 en cumplimiento de lo dispuesto en la Ley 1814 del 2016"
} 